\title{
How patients perceive minor illness and factors influencing seeing a doctor
}

Judy Cantrill, Caroline Morris and Marjorie Weiss School of Pharmacy, University of Manchester, Manchester, UK

It is anecdotally reported that general practitioners (GPs) consider that some of their time is wasted by patients consulting with minor ailments. This study aimed to investigate patients' definitions of minor ailments and explore the reasons behind their decision to seek a GP consultation about ailments that they perceive to be minor. Qualitative interviews were conducted with a purposive sample of 19 adult patients from two demographically and socially diverse general practices in England. Interviewees' views on (i) the types of symptoms and illnesses they thought of as minor ailments and (ii) the precipitating factors that had influenced their decision to consult a GP about a minor ailment were explored. What interviewees considered as minor ailments depended not only upon factors relating to the current condition (such as severity), but also other issues (such as previous experience and knowledge).

Although a condition that could be self-managed was considered a minor ailment; a minor ailment was not necessarily synonymous with a condition that could be handled alone. It is therefore unhelpful to think of specific conditions as being minor or major or to dismiss all minor ailment consultations as a waste of GP time. From a patient perspective the decision to consult their GP about a minor ailment may be a rational and evaluated one. The importance of understanding why some patients consult with minor ailments, and allowing them to retain choice in the way they seek advice, should not be underestimated when considering ways of increasing access to health professionals.

Key words: general practitioner consultation; minor ailment; patients' perceptions

Received: March 2005; accepted: December 2005

\section{Introduction}

In recent years societal expectations of health care have increased. The effect of raising patient expectations has been increased patient demand and a resultant strain on general medical services (Gillam and Pencheon, 1998). It is often reported anecdotally that policy makers and general practitioners (GPs) consider that consultations about minor ailments are responsible for a large proportion of 'inappropriate' demand. Indeed, GPs are often consulted about ailments that they consider to be

Address for correspondence: Judy Cantrill, The Drug Usage and Pharmacy Practice Group, School of Pharmacy and Pharmaceutical Sciences, University of Manchester, Oxford Road, Manchester, M13 9PL, UK. Email: judith.cantrill@ manchester.ac.uk minor (Morris et al., 2003). Some GPs recently questioned stated that over one fifth of their appointments could have been dealt with by a pharmacist. (Anon, 2003) Reducing demand on GP services, increasing access to other health professionals particularly for minor ailments and, indeed, the whole area of 'self-care' is a focus of Government health policy. The rapid expansion of National Health Service (NHS) Direct (Department of Health, 1999a), the introduction of NHS Primary Care walk-in centres (Department of Health, 1999b) and the recent Government report 'Self-care - a real choice' (Department of Health, 2005) are indicative of this.

An observational study in general practice (Stoddart et al., 2003) has shown that younger age and having a problem for a short time are independently associated with receiving 'same-day' care. 
Furthermore, rapid access to care was rated as more important than seeing a known doctor for two hypothetical illness episodes (an acute cough with a sore throat and temperature and chronic back pain). Patient choice has been widened by a greater role for pharmacists, negating the need to visit the GP, stemming to some degree from the increased number of medicines being deregulated from 'prescription only' to 'pharmacy' status. Choice is being increased still further by the introduction of the 'transfer of minor ailments' from general practice to community pharmacy schemes. Such schemes allow pharmacists to 'prescribe' specified overthe-counter (OTC) medicines for minor ailments on the NHS for patients who are exempt from prescription charges. This therefore removes the financial disincentive to visit a pharmacy. The seminal 'Care at the Chemist' scheme, although successful, was only able to transfer a relatively small percentage of such consultations (Hassell et al., 2001). Despite the fact the study did not explore the reason why this was so, similar schemes are being rolled out nationally (Bellingham, 2002; 2004).

Although it has been identified that sometimes a mismatch exists between the lay and professional interpretation of what constitutes a minor ailment consultation (Morris et al., 2003), research on patients' perceptions of minor ailments is sparse. Furthermore, the many reasons why patients may make the choice to consult their GP have been the subject of a wide variety of research (Campbell and Roland, 1996; Thorsen et al., 2001). Indeed, two key articles have identified that the way in which people respond to illness is inextricably linked to their personal and social circumstances (Mechanic and Volkart, 1960; Zola, 1973). While both doctors and patients address physical agendas to a similar high degree, patients present emotional agendas to a far greater extent than doctors address these concerns. (Campion et al., 1992) However, despite the extensive research on consulting in general, no research has been placed explicitly and overtly in the minor ailment context. In recent years, researchers have investigated patients' reasons for consulting for cough (Cornford et al., 1993; 1998; Wyke et al.,1990), dyspepsia (Delaney,1998; Lydeard and Jones, 1989) and irritable bowel syndrome (Kettell et al., 1992). Whilst these conditions may be considered to be minor from a researcher's, professional or clinical perspective they did not elicit whether patients perceived their symptoms in this light. The aim of this study was to (i) investigate how patients' define minor ailments and (ii) explore the reasons behind their decision to consult their GP about ailments they perceive to be minor. In contrast to previous work, patients placed their own interpretation on the term minor ailment.

\section{Method}

As this was an exploratory study, the flexibility of a qualitative approach was required. Face to face interviews were conducted with patients consulting one GP from each of two demographically and socially diverse practices (practice A and practice B) in the West Midlands, England. At the outset 20 interviews were planned. However, the final sample size remained flexible with the intention that interviews would be continued until no new themes, issues and topics were emerging from the interviewees.

Patients were eligible for interview if they had experienced an illness episode that they considered to be a minor ailment in the two weeks prior to their GP appointment. Patients with language difficulties, where English was not the first language or appearing confused were excluded from the study. These interviews formed one part of a larger study. The previous stage involved a short, structured interview with all patients immediately prior to their consultation with these same two GPs (Morris et al., 2003). To ensure that patients did not feel uncomfortable about consulting their GP these questions were framed in a very general way. Firstly identifying whether the patient had experienced a minor ailment within the previous two weeks, then discussing how that ailment had been managed (use of medicines and pharmacies, etc.), before eliciting whether their GP visit was related to this illness episode. As this previous stage ascertained whether consulting patients had experienced what they considered to be a minor ailment in the previous two weeks, it acted as a filter for recruiting patients for the present qualitative study. For patients aged 16 years or under interviews were requested from, and conducted with, the accompanying adult.

Sampling was undertaken purposively. Thus the researcher approached both male and female patients, patients of varying age and those with and without children. In addition, the time of 
recruitment within surgery sessions was varied (to capture working and non-working patients) and the demographic characteristics of the sample monitored regularly during recruitment to ensure that there was sufficient diversity within the final sample. Eligible patients were given verbal details about the interview, told that refusing to participate would in no way affect their future care and asked if they were willing to participate. Patients agreeing to participate were then given full written information about the study and a time and place for the interview to take place (at a later date) were agreed. It was made clear that they were free to change their mind at any time about participation either before or during the interview without comprising their future care. C.J.M conducted the interview, using a schedule comprising open questions to explore the types of symptoms and illnesses that interviewees thought of as minor ailments. This included both questions specific to their most recent minor ailment episode and general questions. More views were elicited by prompting with specific symptoms, generally perceived from a clinical perspective as minor ailments, including cystitis, hayfever, headaches and indigestion. Factors influencing the decision to consult the GP about a minor ailment were explored by focusing on specific illness episodes from the past. Interviewees were therefore encouraged to think and talk about any previously experienced minor illness episodes for which they had consulted their GP. All interviews were audio-taped and transcribed verbatim with permission.

Content analysis (Bowling, 1997) with an element of constant comparison (Pope et al., 2000) was undertaken by C.J.M in an explicit and systematic way. This involved thorough and repeated readings of the transcripts to identify broad distinctions or themes between quotations relating to the main topic areas. From this, categories were developed into which data were coded. These categories were continually refined by subsequent reviews of the data and hence were developed on an ongoing basis as understanding of the area increased and improved. This formed the basis of the data coding scheme. A sample of the transcripts was then independently reviewed by another member of the research team. The final results were subsequently reviewed by group discussion between all three authors to help ensure the validity of the findings.
Table 1 Demographic characteristics of the interviewees $(n=19)$

\begin{tabular}{ll}
\hline Variable & Sample characteristics \\
\hline Gender & Female $(n=13)$; Male $(n=6)$ \\
Age & Mean 44 years; range 20-69 years \\
$\begin{array}{l}\text { Focus of initial } \\
\text { consultation }\end{array}$ & $\begin{array}{l}\text { Interviewee }(n=16) \text {, Child of the } \\
\text { interviewee }(n=3)\end{array}$ \\
$\begin{array}{l}\text { Formal } \\
\text { qualifications }\end{array}$ & $\begin{array}{l}\text { None }(n=9) ; \mathrm{N}^{\prime} \text { level/GCSE }(n=7) ; \\
(n=1)\end{array}$ \\
$\begin{array}{l}\text { Occupational qualification }(n=2) ;{ }^{\prime} \text { ' levels } \\
\text { status }\end{array}$ & $\begin{array}{l}\text { Employed }(n=10) ; \text { Retired }(n=3) ; \\
(n=2) ; \text { Student }(n=1)\end{array}$ \\
$\begin{array}{l}\text { Eligible for } \\
\text { prescription } \\
\text { charges }\end{array}$ & Yes $(n=11) ;$ No $(n=8)$ \\
\hline
\end{tabular}

As this work was undertaken in 1998 ethical approval was not sought. However, we wish to acknowledge that ethical approval would today be required for a study such as this.

\section{Results}

\section{Interview sample}

Twenty-six patients were invited to participate in the interview. Six patients declined this invitation outright. As one interview was abandoned after three unsuccessful attempts to contact the interviewee, a total of 19 interviews took place. The average length of the interview was approximately half an hour. Fourteen took place at the GP practice and five in the interviewee's home. Brief demographic characteristics of the interviewees are shown in Table 1.

\section{Definition of minor ailments}

\section{Conditions perceived as minor ailments}

Interviewees spontaneously agreed that coughs, colds, influenza-like symptoms and general aches and pains constituted minor ailments. On prompting with specific 'minor' symptoms (cystitis, hayfever, headaches and indigestion), widely differing views emerged ranging from this was a significant health problem to not being rated as a symptom:

I don't think it's minor, it's so painful. [cystitis] 
It's nothing I've just got to live with it. [hayfever]

Well, I wouldn't call that a symptom even. [headache]

\section{The decision to classify an illness episode as a minor ailment}

Previous experience and personal knowledge of an illness was key in the interviewees' decision to classify an illness episode as a minor ailment. For most interviewees a minor ailment appeared to be synonymous with a condition that they felt able to self-manage. Some such ailments were described in terms of their known self-limiting or episodic nature as a result of previous experience:

Things like piles, headaches, sickness things that perhaps only crop up every now and again or they might come and go.

Other minor ailments were perceived in this way because the interviewee knew both what the condition was and had the knowledge, either from personal experience or the experiences of lay others, to be able to treat it.

Things like indigestion I take the normal remedies and if that cures it then fine.

Previous professional advice also played a key part in how interviewees viewed their symptoms:

Over the past 18 months I've had dizziness.... I've been off colour, trembling. ... I know when it's coming on now from the past, so now I don't bother (the GP).... I can live with that now I know its happening.

It is notable that although some interviewees had not experienced an illness they made a judgement as to whether it was a minor ailment based on the experiences of others:

No, [hayfever is not a minor symptom] I don't particularly suffer with that but I've got two sons who suffer with it and they do suffer.

\section{Box 1 Factors influencing the decision to classify an illness episode as a minor ailment}

1) Symptom severity (personal or vicarious experience)

2) Risks of self-diagnosis

3) Knowledge of how to self-manage

4) Diagnosis previously made by a professional

Another interviewee gave a clear indication of the effect that personal circumstances can have on the perception of the risks involved with self-diagnosis. Three close family members had experienced a brain haemorrhage:

I would have said in the past [a headache] was minor, but in view of what's happened to my family now I don't know, I'm not sure how I would view that in the future.

The key factors underlying the decision to classify in their own mind an illness episode as a minor ailment are shown in Box 1.

\section{The decision to consult}

Although logically you would expect people not to consult about an ailment they considered minor, our results suggest that this is too simplistic a view. Twelve of the interviewees volunteered during recruitment that their consultation that day was related to a perceived minor ailment episode. This suggests that some patients consider their GP to have a role to play in minor ailment management. Data summarized in Table 2 gives brief details about these interviewees' symptoms and shows the factors that had influenced their decision to consult. The factors shown in Table 2 were reconfirmed by these, and other, interviewees when discussing other minor ailment consultations they had made in the past.

Their decision can be broadly divided into two categories. For some ailments there was no doubt in the interviewee's mind that they were experiencing a minor ailment at the point of the consultation. For others, although deep down they considered that they were experiencing a minor ailment, an underlying doubt existed. 
Table 2 Interviewees consulting about their minor ailment episode

\begin{tabular}{|c|c|c|}
\hline Identity no. & Symptom/problem & Reasons for consulting \\
\hline $\mathrm{A} 01$ & Cough/cold & $\begin{array}{l}\text { Severity of symptoms } \\
\text { Perception it was asthma }\end{array}$ \\
\hline A02 & Earache in child & $\begin{array}{l}\text { Severity of symptoms } \\
\text { Persistence of symptoms }\end{array}$ \\
\hline A04 & Diarrhoea and sickness & $\begin{array}{l}\text { Severity of symptoms } \\
\text { Persistence of symptoms }\end{array}$ \\
\hline A05 & Post shingles skin rash & $\begin{array}{l}\text { Persistence of symptoms } \\
\text { Medical certificate required }\end{array}$ \\
\hline $\mathrm{A} 07$ & Twisted knee & $\begin{array}{l}\text { Severity of symptoms (pain) } \\
\text { Affecting normal daily activities }\end{array}$ \\
\hline A09 & Swollen eye & $\begin{array}{l}\text { Severity of symptoms } \\
\text { Persistence of symptoms } \\
\text { No improvement with OTC medicine } \\
\text { Advised by pharmacy staff to consult }\end{array}$ \\
\hline B01 & Fungal rash & $\begin{array}{l}\text { When previously experienced GP prescribed OTC anti-fungal cream } \\
\text { (Canesten }{ }^{\circledR} \text { ). Consulting on this occasion to obtain the same cream }\end{array}$ \\
\hline B03 & $\begin{array}{l}\text { Headache, pyrexia } \\
\text { and back pain in child }\end{array}$ & $\begin{array}{l}\text { ‘l couldn't cope with it’ } \\
\text { Unusual symptom of back pain } \\
\text { Frightened it was meningitis }\end{array}$ \\
\hline B04 & Cold & $\begin{array}{l}\text { Family member ill with emphysema, pneumonia and bronchitis } \\
\text { therefore 'it needed sorting quickly' }\end{array}$ \\
\hline B05 & Leg cramps & $\begin{array}{l}\text { Reassurance - taking long-term tamoxifen - had read in patient } \\
\text { information leaflet of side effect of blood clots }\end{array}$ \\
\hline B06 & Swollen foot & $\begin{array}{l}\text { Concerned it was induced by prescribed morphine tablets } \\
\text { Rang receptionist - she spoke to GP who advised patient to make an } \\
\text { appointment }\end{array}$ \\
\hline B09 & Back pain & $\begin{array}{l}\text { Persistence of symptoms for six days } \\
\text { Assumed initially muscular post gardening, now needed reassurance }\end{array}$ \\
\hline
\end{tabular}

\section{Definitely a minor ailment}

The importance of a fast resolution for minor ailments was made in two different contexts. One interviewee acknowledged that her symptoms were minor and would undoubtedly resolve with time, but a prescription only medicine (POM) would potentially improve her well being by speeding up the process:

I have thought well perhaps this could be dealt with much quicker with antibiotics, it may be minor but it is something that I think needs dealing with by the doctor really, unless you want to wait with all the pain for it to go on its own.... I just want something quick.

It appears that this interviewee considered medicines prescribed by the doctor to be 'stronger' than those available OTC and hence would resolve the symptoms more quickly.
Others mentioned instances when a quick recovery was essential due to work commitments:

[I've consulted with] a cold, probably it was 'flu, it wasn't deadly serious but then again I wanted to get rid of it as quick as possible because I was working at the time you see.

\section{Another person is worried that the condition is not a minor ailment}

Three interviewees identified that sometimes they had consulted about a minor ailment to allay someone else's fears. These lay influences included partners and parents:

I was suffering from quite bad indigestion ... so I came to the doctor, but it was me wife that told me to come then because I was getting the irritation across the chest. 
Other [minor] things ... because me mum tells me to.

The quotation below highlights the potential importance of advice given informally by friends and acquaintances that are health professionals:

I started getting cramp and pins and needles ... [but I consulted] only because the nurse next door but one to me sister thought it was serious, she thought that it was a heart attack.

\section{Underlying doubt as to the minor nature of the condition}

Where doubt existed it was often due to the severity of symptoms and their duration. Often the key precipitating factor for the consultation was that the symptoms were more severe and/or had persisted longer than when a similar condition had been experienced in the past:

He's [her son] had an ear infection before and if its just normally an earache it normally goes off within a few hours or so but he'd been up all night and I thought well he isn't one for staying off school he's quite good so I thought it must be a bit worse than just [normal] earache so that's why I'd taken him to the doctors.

(A02)

One interviewee stated that the timing within the week of her symptoms would affect her decision whether or not to consult her GP. She identified a need for additional reassurance as the weekend approached because of the difficulties of gaining access to GP services at this time:

I always say if it doesn't go by Thursday you've got to get in to the doctor cos you've got to go over the weekend and then you always have panic stations.

Lack of knowledge or experience of the symptoms also added an element of doubt. Although a symptom was probably minor, it only became selfmanageable, after a diagnosis had been made by a health professional. Hence if there was any doubt

\section{Box 2 Factors influencing the decision to make a minor ailment consultation}

1) Perception of the severity of the symptoms.

2) Persistence of the symptoms.

3) To obtain/confirm the diagnosis.

4) Individual need for reassurance.

5) A consultation had been made for the same problem in the past.

6) There was a desire for a speedy resolution to the problem.

7) Perception of the need for a prescription.

8) To obtain a medical certificate.

9) Advice given by a third party.

about precisely what a condition was, GP advice was needed:

If I thought there was something sore somewhere [piles] I'd want a doctor to tell me that's what it was in the first instance.

The key factors identified by these data as potentially precipitating minor ailment consultations are summarized in Box 2.

\section{Discussion}

This study has addressed how patients perceive minor ailments and the reasons why they may choose to consult their GP about a minor ailment. Their perceptions have been placed exclusively, explicitly and overtly in the minor ailment context, using their own interpretation of the term. Clearly, from a patient perspective making a minor ailment consultation is a rational and evaluated decision. However, the results are limited by the fact that this study was conducted in one geographical area of England and in only two GP practices. Although data saturation appeared to have been achieved at 19 interviews it is possible that further interviews may have elicited more different perspectives. Furthermore, recruiting through GP practices may have over-represented inherently high users of GP services and meant that interviewees may have been predisposed to giving views that would be approved of by their GP.

With health policy focused on increasing patient choice and the expansion of the "transfer of minor 
ailments' from general practice to community pharmacy schemes (Bellingham, 2004) it is imperative to understand minor ailments from the patients' perspective. Most interviewees spontaneously agreed that coughs, colds, influenza-like symptoms and general aches and pains constituted minor ailments. Indeed, these same symptoms were cited as minor in an interview study of pharmacy customers conducted by Hassell et al. (1997). Colds, headaches and gastrointestinal disturbance were the most commonly reported minor ailments in a questionnaire survey of carers' management of minor childhood ailments (Cantrill et al., 1996). However, it is not always helpful to think of specific conditions as being minor or major. The data from this study have provided insights into patients' constructions of the term minor ailment. What is considered minor depends not only upon condition-related issues (such as severity), but also other issues (such as previous experience and knowledge). Notably, a condition can change from being major to minor. Furthermore, sometimes a condition that would be viewed as serious from a professional perspective (eg, an acute exacerbation of asthma) may be considered minor by the patient simply because they have the experience and knowledge of how to deal with it (Morris, 2000).

Although patients in the present study viewed a condition that could be self-managed as a minor ailment; a minor ailment was not necessarily synonymous with a condition that could be handled alone. Superficially, it would appear a logical assumption that patients would be likely to consult if they consider their condition as serious, and unlikely to consult if they perceived their condition as a minor ailment. However, we know that patients sometimes consult about ailments they perceive to be minor (Morris et al., 2003). This study used a qualitative approach to explore the reasons why.

It is notable that whatever reasons patients gave for making a minor ailment consultation, it was an evaluated decision and they clearly viewed it as a rational course of action. This held true even if they were consulting to allay the concerns of a third party. A noteworthy feature of all the influences identified was that, with the exception of consulting to obtain a medical certificate, a single underlying factor potentially affected them all. This related to personal knowledge, or lack of knowledge, about the symptoms and their treatment. Furthermore, the presentation or development of a minor ailment compared to previous experiences of a similar condition was key. These same factors are likely to influence advice given by a third party. That person's advice is likely to be informed by their own previous experience or personal knowledge of the symptoms about which their advice is sought.

Sometimes patients consulted purely to access something that was otherwise unavailable to them (a POM or a medical certificate). Despite the fact that patients made minor ailment consultations, they were taking control of their illness. They made a decision to utilize the GP to access what they felt they needed. This need may have been a specific medicine, professional advice, reassurance or diagnosis. While many of the reasons cited have been identified previously in research investigating patients' decisions to consult in general (Mechanic and Volkart, 1960; Zola 1973; Campbell and Roland, 1996) this is the first time they have been placed specifically in the minor ailment context.

It is clearly unhelpful to dismiss all minor ailments as a waste of GP time. It is therefore important that GPs and, indeed, all health professionals support patients in their decision making by working together to ensure that patients have convenient access to both the professional help and the information they perceive they need, when they think they need it and from whom they prefer. Nurses within GP practices (Horrocks et al., 2002), nurses at walk-in centres (Horrocks et al., 2002), NHS Direct (Department of Health, 1999a) and community pharmacists (Hassell et al., 1997; Tully et al., 1997; Bellingham, 2004) are all potentially alternative sources of support and advice. The focus of health policy should be on widening choice further and the provision of a range of services to meet patient need.

\section{Acknowledgements}

We are grateful to the two GP practices and all those patients who contributed to this study by taking part in the interview.

\section{References}

Anon. 2003: Public still widely consult GPs on minor illnesses. Pharmaceutical Journal 270, 70.

Bellingham, C. 2002: Pharmacists who prescribe: the reality. Pharmaceutical Journal 268, 238. 
Bellingham, C. 2004: How the minor ailments service works. Pharmaceutical Journal 272, 115-16.

Bowling, A. 1997: Research methods in health. Investigating health and health services. Buckingham: Open University Press.

Campbell, S.M. and Roland, M.O. 1996: Why do people consult the doctor? Family Practice 13, 75-83.

Campion, P.D., Butler, N.M. and Cox, A.D. 1992: Principle agendas of doctors and patients in general practice consultations. Family Practice 9, 181-90.

Cantrill, J.A., Johannesson, B., Nicolson, M. and Noyce, P.R. 1996: Management of minor ailments in primary schoolchildren in rural and urban areas. Child Care Health and Development 22, 167-74.

Cornford, C.S. 1998: Why patients consult when they cough: a comparison of consulting and non-consulting patients. British Journal of General Practice 48, 1751-54.

Cornford, C.S., Morgan, M. and Ridsdale, L. 1993: Why do mothers consult when their children cough? Family Practice 10, 193-96.

Delaney, B.C. 1998: Why do dyspeptic patients over the age of 50 consult their general practitioner? A qualitative investigation of health beliefs relating to dyspepsia. British Journal of General Practice 48, 1481-85.

Department of Health. 1999a: NHS healthcare advice direct to your living room. DoH press release 1999/0738.

Department of Health. 1999b: NHS Primary Care Walk-in centres. Health Services Circular, HSC 1999/116.

Department of Health. 2005: Self care - a real choice. London: Department of Health.

Gillam, S. and Pencheon, D. 1998: Managing demand in general practice. British Medical Journal 316, 1895-98.

Hassell, K., Noyce, P.R., Rogers, A., Harris, J. and Wilkinson, J. 1997: A pathway to the GP: the pharmaceutical 'consultation' as a first port of call in primary health care. Family Practice 14, 498-502.

Hassell, K., Whittington, Z., Cantrill, J., Bates, F., Rogers, A. and Noyce, P. 2001: Managing demand: transfer of management of self limiting conditions from general practice to community pharmacies. British Medical Journal 323, 146-47.

Horrocks, S., Anderson, A. and Salisbury, C. 2002: Systematic review of whether nurse practitioners working in primary care can provide equivalent care to doctors. British Medical Journal 324, 819-23.

Kettell, J., Jones, R. and Lydeard, S. 1992: Reasons for consultation in irritable bowel syndrome: symptoms and patient characteristics. British Journal of General Practice 42, 459-61.

Lydeard, S. and Jones, R. 1989: Factors affecting the decision to consult with dyspepsia: comparison of consulters and nonconsulters. Journal of the Royal College of General Practitioners 39, 495-98.

Mechanic, D. and Volkart, E.H. 1960: Illness behavior and medical diagnoses. Journal of Health and Human Behavior 1, 86-94.

Morris, C.J. 2000: Patients' and general practitioners' perceptions of minor ailments, $\mathrm{PhD}$, University of Manchester, UK.

Morris, C. J., Cantrill, J.A. and Weiss, M.C. 2003: Minor ailment consultations: a mismatch of perceptions between patients and GPs. Primary Health Care Research and Development 4, 365-70.

Pope, C., Ziebland, S. and Mays, N. 2000: Analysing qualitative data. British Medical Journal 320, 114-16.

Stoddart, H., Evans, M., Peters T.J. and Salisbury, C. 2003: The provision of 'same-day' care in general practice: an observational study. Family Practice 20, 41-47.

Thorsen, H., Witt, K., Hollnagel, H. and Malterud, K. 2001: The purpose of the general practice consultation from the patient's perspective - theoretical aspects. Family Practice 18, 638-43.

Tully, M.P., Hassell, K. and Noyce, P.R. 1997: Advice-giving in community pharmacies in the UK. Journal of Health Services Research and Policy 2, 38-50.

Wyke, S., Hewison, J. and Russell, I.T. 1990: Respiratory illness in children: what makes parents decide to consult? British Journal of General Practice 40, 226-29.

Zola, I.K. 1973: Pathways to the doctor - from person to patient. Social Science Medicine 7, 677-89. 